\title{
EDUCAÇÃO AMBIENTAL, TRANSFORMAÇÃO E DESENVOLVIMENTO LOCAL: ANÁLISE DE UMA EXPERIÊNCIA PEDAGÓGICA
}

\author{
Karina Barreto da Silva ${ }^{1}$ \\ Simoni Jacomini de Souza ${ }^{2}$ \\ Sabino Joaquim de Paula Freitas ${ }^{3}$
}

Resumo: A escola é uma instituição a que todos os segmentos da sociedade têm acesso em algum período da vida e, por isto, pode ser um espaço privilegiado para a formação de consciência ecológica e para a transformação de práticas sociais que interferem negativamente no meio ambiente. $O$ presente trabalho foi realizado a partir da pesquisa bibliográfica sobre a temática da Educação Ambiental, articulando o referencial teórico com um projeto de trabalho desenvolvido por uma escola de Belo Horizonte, cuja proposta pedagógica foi fundamentada nos princípios que norteiam a Política Nacional de Educação Ambiental. Os resultados obtidos demonstram que a referida proposta se vincula a práticas educativas comprometidas com 0 empoderamento e o desenvolvimento local.

Palavras-chave: Sustentabilidade; Intersetorialidade; Desenvolvimento Local. 


\section{Introdução}

O período do pós Segunda Guerra Mundial até o final de 1970, trouxe denúncias de graves questões relacionadas à degradação do meio ambiente. Segundo Silva (2012), em busca da hegemonia mundial, as duas potências vencedoras, EUA (capitalista) e a antiga URSS (socialista), acirraram disputas de armamentos, testes nucleares, avanços tecnológicos, além de uma intensa industrialização mundial. Esse contexto favorecia as reflexões e discussões sobre os impactos ambientais: extração e uso exagerado dos recursos naturais, poluição, destruição de ecossistemas naturais, acirramento das desigualdades sociais, dentre outros aspectos. A partir de 1970, vários movimentos sociais organizados em todo o mundo passaram a se preocupar com os problemas ambientais gerados a partir do desenvolvimento econômico: A Conferência das Nações Unidas sobre Meio Ambiente em Estocolmo (1972), a Conferência Intergovernamental de Educação Ambiental de Tblisi, na Geórgia (1977), os relatórios Meadows (1972), Tinbergen (1978), Laszlo (1977), que estabeleceram limites ao crescimento econômico, dentre outros.

No Brasil, entre os anos de 1970 e 1980, vários movimentos, partidos políticos, secretarias, ministérios e organizações não governamentais foram criados, com o intuito de discutir e propor ações ligadas à questão ambiental. Silva (2012) aponta que em 1975 o Brasil realizou o Primeiro Encontro Nacional sobre Proteção e Melhoria do Meio Ambiente, e em 1977 foi assinado pela Secretaria Especial do Meio Ambiente e pelo Ministério do Exterior o documento "Educação Ambiental". Paralelamente, o setor privado também passou a considerar o apelo ecológico, ofertando produtos menos agressivos ao meio ambiente, ainda que por motivação essencialmente econômica.

A preocupação ecológica atinge a diversos segmentos sociais, tanto políticos, como religiosos, culturais e científicos, no sentido de se desenvolver uma consciência que associe o desenvolvimento tecnológico à sustentabilidade (LIMA, 1997). Esta preocupação, até então inexistente no contexto da sociedade industrializada, passou a merecer sucessivos estudos e investimentos que possibilitassem o desenvolvimento econômico de forma a diminuir os danos ao meio ambiente.

A ideia de se buscar um desenvolvimento sustentável foi oficialmente apresentada através do Relatório Bruntland, publicado em 1987. Neste relatório, considera-se que o modelo de desenvolvimento econômico das nações industriais é um modelo esgotado. De acordo com Freitas (2004), a crítica que se faz a este modelo é que é impossível se pensar em um desenvolvimento ilimitado a partir de uma base finita de recursos naturais. Assim, ao se pensar um modelo de desenvolvimento, é preciso conciliá-lo ao meio ambiente, adotando uma nova concepção, que deve ter uma abordagem multidimensional, conjugando viabilidade econômica, prudência ecológica e justiça social.

Segundo Lima, "as repercussões desse avanço da consciência ecológica, no meio social se materializam hoje na grande expansão de

revista brasileira educação ambiental 
agências governamentais voltadas para o ambiental, desde esferas municipais até o nível internacional" (LIMA, 1998, p.106), principalmente entre os anos de 1970 e 1980, tanto no exterior como no Brasil. Assim, aos poucos, pessoas e movimentos sociais passaram a se dar conta do potencial destrutivo imposto pelo consumismo, pela necessidade de produzir mais e melhores mercadorias e pela busca desenfreada por lucro.

\section{O despertar de uma cultura ecológica}

A comunidade científica, movimentos ambientalistas, pacifistas, militantes sociais foram os precursores de um movimento de conscientização que, na etapa seguinte, culminou com a atuação de organizações governamentais e não governamentais nacionais e internacionais, que contou com a adesão de segmentos da iniciativa privada, meios de comunicação de massa, grupos religiosos e movimentos sociais organizados.

Para Lima (1998), essa cultura ecológica traz consequências positivas e negativas. Como aspectos positivos, o autor cita a disseminação de informações que influenciam comportamentos e despertam para uma leitura crítica da realidade. Como aspectos negativos, aponta o modismo, a abordagem superficial e unidimensional dos problemas modernos, a banalização e mercantilização da temática e a despolitização do problema, que não investiga as causas profundas e não questiona "o modelo de desenvolvimento econômico, político, cultural e social que Ihe dá sustentação" (1998, p.107). De toda forma, a temática ganhou visibilidade social, científica, cultural e econômica, de forma que se tornou praticamente impossível haver alguma proposta de desenvolvimento que não tenha interface com a questão ecológica. Como toda tendência, a questão ecológica não está isenta dos modismos e reducionismos tão comuns ao nosso tempo. Apesar disto, há pessoas e movimentos organizados que têm exercido grande influência nas discussões e decisões que envolvem o tema.

Muito mais que um modismo, as iniciativas sérias que buscam reaproveitar o maior número possível dos materiais, a reciclagem, a coleta seletiva, a economia, a reutilização e reaproveitamento, dentre tantas outras ações, visam a uma maior qualidade de vida. Pessoas e organizações sintonizadas com a importância de se preservar o meio ambiente trabalham arduamente, muitas vezes como heróis solitários, para desconstruir a cultura do consumismo, pensando exatamente na qualidade de vida das gerações atual e futura.

Para Viola (1987), o Brasil apresenta um cenário em que quatro posições básicas estão em debate: a posição hegemônica da Nova República, em que aspectos democratizantes da economia são instaurados em médio prazo; as posições conservadoras, que pretendem bloquear ou retardar a instauração do capitalismo de bem-estar; a posição socialista, que prevê a estatização do sistema produtivo e restrições drásticas ao mercado; e, por fim, a posição ecologista, "favorável a um modelo de desenvolvimento que combine 
a democratização socioeconômica com a preservação ambiental, com ênfase na qualidade da vida e no consumo coletivo", mais que no crescimento quantitativo e no consumismo. Para o autor, a posição ecologista no debate político pode influenciar as demais posições, "aumentando deste modo as possibilidades de superar o consenso desenvolvimentista predatório que dominou nas últimas décadas na sociedade brasileira" (VIOLA, 1987).

Do ponto de vista da legislação, várias leis nacionais passaram a tratar especificamente da questão ambiental, o que representa um indicativo do quanto o tema está presente na sociedade contemporânea e aponta para a expectativa de organização a partir de interesses coletivos.

Criado pela Lei 6.938 (BRASIL, 1981), o Conselho Nacional do Meio Ambiente - CONAMA é o órgão consultivo e deliberativo do Sistema Nacional do Meio Ambiente - SISNAMA, que é responsável por efetivar a política de meio ambiente do Brasil. O CONAMA tem a função de estudar, auxiliar e propor ao governo as diretrizes para o meio ambiente e os recursos naturais, além de deliberar sobre normas e padrões para o ecossistema ecologicamente equilibrado e essencial à sadia qualidade de vida. É um colegiado representativo de cinco setores, sendo: órgãos federais, estaduais e municipais, setor empresarial e sociedade civil.

Um dos princípios da referida lei se baseia na importância da educação como instrumento importante no processo de conscientização da comunidade, como forma de capacitá-la para a defesa do meio ambiente.

A Constituição Brasileira, de 1988, em seu Artigo 225, Capítulo VI - Do Meio Ambiente, Inciso $\mathrm{VI}$, determina que se deve "promover a Educação Ambiental em todos os níveis de ensino e a conscientização pública para a preservação do meio ambiente". São criados meios jurídicos e administrativos federais, estaduais e municipais voltadas à Educação Ambiental.

Sob esta perspectiva, a presidência da República criou, em 1994, o Programa Nacional de Educação Ambiental (PRONEA), que foi substituído dez anos depois pelo Programa Nacional de Educação Ambiental para Sociedades Sustentáveis (ProNEA), constituindo-se assim a principal referência programática para a elaboração de políticas públicas de Educação Ambiental (EA) em todas as esferas governamentais.

\section{Ecologia, Educação Ambiental e formação para a cidadania}

Neste sentido, espera-se que a escola, ao abordar a questão ecológica de forma transversal e inserir esta temática em seus currículos, possibilite ao educando a formação de uma cultura que contemple atitudes, valores e habilidades necessárias à preservação de condições razoáveis de sobrevivência e desenvolvimento humano sustentável. Concordamos que a EA deve agir sob a ótica da formação de sujeitos e produção de valores comprometida com um ideário emancipatório. Assim, ao enfatizar a dimensão ambiental, entendida como uma correlação de elementos, é necessário ampliar 
a esfera pública, de forma a promover o debate sobre o acesso e sobre as decisões relativas ao uso dos recursos ambientais, considerando o contexto social, econômico, político e ecológico. Nesta perspectiva, o educador torna-se o mediador das relações que os diferentes grupos estabelecem entre si e com o meio ambiente, interpretando e facilitando as ações individuais e coletivas, produzindo novas experiências e aprendizagem.

De acordo com Carvalho (2001), outras correntes pedagógicas anteriores à chamada EA também se preocuparam em contextualizar o sujeito em sua dimensão histórica, social e natural, de forma que não há nada inédito, do ponto de vista metodológico e didático, no que se refere à EA. Segundo a autora, o diferencial da EA, que a caracteriza como uma nova prática educativa que ultrapassa a simples reedição de práticas já utilizadas na educação, "tem a ver com o modo como esta EA revisita esse conjunto de atividades pedagógicas, reatualizando-as dentro de um novo horizonte epistemológico em que o ambiental é pensado como sistema complexo de relações e interações", (CARVALHO, 2001, p. 44).

Desta forma, a EA compreende tanto o ecossistema natural como o espaço historicamente construído e socialmente conflitivo de relações socioambientais, estando o conjunto de prática de EA demarcado por duas diferentes orientações: EA comportamentalista e EA popular.

A EA comportamentalista valoriza o papel da Educação como agente difusor de conhecimentos que irão induzir a mudança positiva de hábitos e comportamentos. Considera que as crianças, por estarem em fase de desenvolvimento cognitivo, apresentam melhores condições que os adultos de internalizar a consciência ambiental, traduzindo-a em comportamentos ecologicamente desejados. Supõe, portanto, "indivíduos cuja totalidade da ação encontra suas causas na esfera da razão e é nesta esfera que se pretende situar as relações de aprendizagem e a formação dos valores" (CARVALHO, 2001, p. 47).

A EA popular associa-se a uma tradição da Educação Popular, que compreende o processo educativo como um ato político, como prática social de formação da cidadania. Propõe formar sujeitos políticos, capazes de agir criticamente na realidade sócio-política e histórica. Considera o indivíduo um ser social e não foca sua ação exclusivamente no comportamento, embora tenha uma herança racionalista que se expressa no conceito de conscientização do indivíduo. Pode utilizar-se, conforme observa Carvalho (2001), de conceitos mais complexos como o de Ação Política, com ações de transformação da sociedade a partir da transformação das relações humanas com o meio ambiente:

O entendimento do que sejam os problemas ambientais passa por uma visão do meio ambiente como um campo de sentidos socialmente construído e, como tal, atravessado pela diversidade cultural e ideológica, bem como pelos conflitos de interesse que caracterizam a esfera pública. Essa Revbea, São Paulo, V. V. 13, № 1: 156-171, 2018. 
transformação das relações com o meio ambiente se dá em um projeto de construção de um novo ethos social, ou seja, de relações estabelecidas a partir de valores libertários, democráticos e solidários (CARVALHO, 2001, p.47).

Como a Educação Popular considera a educação um processo permanente e possível, não há sujeitos prioritários da ação educativa ambiental, embora a Educação Popular tenha se configurado, em grande parte, como educação de adultos. O que difere nesta abordagem é que a educação se dirige a sujeitos capazes de decisão, o que inclui crianças e adultos.

$\mathrm{Na}$ prática, avaliamos que é preciso que os alunos reconheçam a importância da EA em seu contexto, e que tenham a consciência de que, a partir da ação pessoal de cada um, é possível que sejam agentes transformadores, capazes de mudar a realidade à sua volta. Segundo Lima (1998), a consciência ecológica se manifesta como compreensão intelectual de uma realidade, que desemboca em ações e sentimentos pessoais que incidirão nas relações sociais e nas relações do homem com a natureza. Essa realidade transformadora será capaz de transcender para outras realidades, constituindose como um todo.

Nazaré et al. (2017) sugerem três concepções para categorizar a Educação Ambiental: a concepção conservadora, centrada na valorização e proteção do meio ambiente; a concepção pragmática, centrada nas discussões sobre desenvolvimento sustentável, legislação e solução de problemas; e a concepção crítica, "de caráter interdisciplinar para o entendimento da problemática socioambiental, mudança de comportamento coletivo e a formação de sujeitos ecológicos" (NAZARÉ et al., 2017). Segundo Layrargues e Lima (2011), as concepções conservadora e pragmática apresentam-se limitadas, pois compreendem a Educação Ambiental de forma descontextualizada histórica, social e politicamente, numa visão reducionista do ser humano e do ambiente. Já a perspectiva alternativa, representada pela concepção crítica, supõe a compreensão dos mecanismos de reprodução social, das relações socioculturais e de classes entre o ser humano e a natureza (LAYRARGUES, LIMA, 2011). Para o presente trabalho, considerouse a perspectiva da Educação Ambiental Crítica, incluindo aspectos de diferentes correntes que esta concepção aglutina, a partir da ideia de que é importante contextualizar e politizar o debate sobre as contradições existentes nos modelos societários e os impactos socioambientais experimentados no nível local e global.

\section{Educação Ambiental e desenvolvimento local: caminhos convergentes}

Conforme Guimarães (2007), é fundamental que o educador ambiental seja capaz de realizar a leitura da complexidade do mundo, evitando reproduzir o passado e transformar o presente, participando na organização e na pressão para alcançar o novo. $O$ autor percebe o educador ambiental como uma 
liderança, que irá dinamizar o movimento coletivo de resistência a partir de sua prática pedagógica.

De acordo com Gonçalves (1993), a dimensão política da ecologia tem a ver com a consciência de que há limites para a ação humana em contato com o meio ambiente. A partir desta constatação, a dimensão política se relaciona com a questão central: quem irá definir os limites? Neste sentido, o autor observa que a questão ambiental é também uma questão política, em que relações de poder estão em jogo, bem como diferentes interesses. Assim, as propostas para solução da questão ambiental voltadas aos desastres ecológicos e aos desequilíbrios sobre os ciclos naturais decorrem de decisões políticas e econômicas tomadas pelos detentores do poder hegemônico. A resolução destes problemas, mais que uma preocupação exclusiva de ecologistas e ativistas, exige mudanças estruturais de poder e de produção, que só poderão ser tomadas de forma satisfatória se a sociedade civil se apropriar da agenda ecológica.

O desenvolvimento local supõe o enfrentamento dos problemas que atingem uma determinada comunidade, promovendo a participação, o empoderamento e a efetivação da cidadania dos sujeitos envolvidos tanto na identificação como na resolução dos problemas. Na educação formal, alunos e corpo docente são sujeitos que exercem importantes papéis e que podem construir experiências significativas no fortalecimento da participação e no empoderamento dos sujeitos. Por isto as experiências isoladas não se constituem fenômenos menos importantes, mas podem se tornar espaços ricos de inclusão, participação, solidariedade e de construção de um trabalho coletivo.

De acordo com Jaume Carbonell (2002), a escola, como parte de um sistema maior, é um espaço de reprodução das relações sociais, quando mantém uma série de práticas que reforçam e não rompem com os processos de exclusão. Porém, é também um espaço potencial de resistência, de embates e confrontos, na medida em que os atores que integram a comunidade escolar têm valores, perspectivas, dinâmicas e comportamentos que podem resistir a modelos verticalizados de gestão escolar. Assim, os últimos vinte anos mostram que há uma renovação nas práticas pedagógicas de professores, a inclusão de temas até então ignorados no currículo escolar e uma crescente ampliação das propostas que contemplam o nível local, reconhecendo a realidade do aluno como espaço essencial de educação, e não mais de negação. Esta vocação para a ação política conduz a práticas inovadoras que podem contribuir para a desconstrução de modelos autoritários e para a ampliação da democracia.

Segundo Morin (2007), há saberes fundamentais que a educação do futuro deveria se preocupar em ensinar. Dentre esses saberes, o autor aponta a importância de se ensinar a condição humana, em sua identidade complexa e sua identidade comum, reconhecendo a unidade e complexidade humana, que deveria ser o objeto essencial de todo o ensino. Morin (2007) indica, também, a importância de se ensinar a identidade terrena, reconhecendo a era planetária, Revbea, São Paulo, V. V. 13, № 1: 156-171, 2018. 
em que todas as partes do mundo se tornam solidárias, ainda que as opressões e a dominação não tenham desaparecido. Estes conhecimentos, nesta perspectiva, buscam aproximar o objeto de estudo das experiências reais e da própria organização social, fazendo com que a escola não seja uma instituição estanque, mas que traduza as aspirações da própria sociedade em que se insere.

Assim, ao pensarmos o homem em interação com 0 ambiente, precisamos, exatamente, reconhecer a condição humana em sua complexidade e em sua identidade, principalmente se considerarmos as condições de sobrevivência. Neste sentido, os atuais problemas ambientais, originados a partir de uma multiplicidade de fatores - sociais, ambientais, culturais, econômicos, ideológicos, tecnológicos, dentre outros - toma dimensão significativa, se considerarmos o homem em sua totalidade.

De acordo com Carvalho (2004), a consciência ambiental transformadora possibilita a formação de um sujeito humano individual e coletivo. A partir do sujeito coletivo, os comportamentos individuais podem se adequar a atender melhor aos interesses da coletividade, não apenas do indivíduo. Esta dimensão política pode ser desenvolvida a partir da EA crítica, que, segundo a autora, busca compreender as relações estabelecidas entre a sociedade e a natureza, bem como as formas de intervenção possíveis e sustentáveis sobre os problemas e conflitos ambientais. Por outro lado, a abordagem comportamental restringe a visão dos processos sociais e subjetivos dos sujeitos, reduzindo-os à sua dimensão racional e ignorando a dimensão social, o que faz com que não consiga assegurar a continuidade entre a razão e as atitudes.

A consciência ecológica não se constitui a partir da indução de comportamentos, numa perspectiva individualista, pois o sujeito pode estar preocupado com a preservação do seu meio ambiente local, sem que tenha qualquer compromisso com um pacto solidário global. Desta forma, a capacidade da Educação promover valores ambientais se traduz, muito mais que pela aquisição de informações, mas pela aprendizagem ativa, pela construção de sentido em uma dimensão holística. Segundo Carvalho (2001, p.48), a internalização de uma consciência ecológica emancipatória "não se dá apenas por um convencimento racional sobre a urgência da crise ambiental, mas sobretudo implica uma vinculação afetiva com os valores éticos e estéticos desta visão de mundo".

Diante disto, uma questão que sempre vem à tona quando o assunto é consciência ecológica refere-se ao papel da Educação no processo de conscientização dos sujeitos. Como a escola é, por excelência, a instituição social de Educação a que todos os segmentos da sociedade têm acesso em algum período da vida, entende-se que este pode ser um espaço privilegiado para a formação de consciência ecológica e para a transformação de práticas sociais que interferem negativamente no meio ambiente. 


\section{A complexidade como paradigma para a educação}

Em uma sociedade que "desafia a instituição escolar, atribuindo-Ihe múltiplas funções que em outros tempos e espaços não eram de sua responsabilidade e a própria sociedade é desafiada quanto aos modelos de educação constituídos e adotados até então", torna-se necessário uma redefinição do papel social da escola pública. Isto porque esta "passa a incorporar um conjunto de responsabilidades que não eram vistas como tipicamente escolares, mas que, se não estiverem garantidas podem inviabilizar o trabalho pedagógico." (MOLL, 2009, p. 17). Quando uma criança chega à escola, traz consigo as diferentes faces de sua condição social e das contradições que permeiam a vida em determinado tempo e espaço. Por isto, muitas vezes, na busca por um ensino de qualidade, que seja significativo e faça sentido para o aluno, a escola incorpora em suas práticas aspectos que dizem respeito à saúde, à cultura, à filosofia, à ética, à solidariedade e à cidadania.

A abordagem do processo educacional empregada em uma proposta de EA deve enfatizar os aspectos sócio-político-culturais, reconhecendo o aluno como sujeito de seu processo educativo, e não apenas um receptor de informações. O educador Paulo Freire, que vinha do exílio na Europa, onde aprendeu muito do que trouxe de volta para o Brasil, foi o precursor desta abordagem, contribuindo para a criação de um método de ensino que partia sempre do conhecimento inerente do povo, introduzindo os saberes populares na análise sócio-histórica da realidade. Nesta perspectiva, é importante reconhecer a existência de alunos concretos, vivendo em tempos e espaços definidos, inseridos em um contexto social, econômico, político e cultural, ou seja, um contexto histórico (MIZUKAMI, 1986).

Nesta abordagem, também chamada de sociointeracionista, considerase o homem em sua vocação de ser sujeito (vocação ontológica) e as condições objetivas em que vive. Neste contexto, a construção do conhecimento está ligada a um processo de tomada de consciência - ou conscientização, conforme Paulo Freire (1987). Esse processo é sempre inacabado, contínuo e progressivo e é nesta perspectiva que uma proposta de EA deve estar baseada, considerando a realidade em que os sujeitos envolvidos estão inseridos. O que se pretende é perceber e reconhecer tanto educandos como educadores como sujeitos socioculturais, inseridos em um contexto que não pode ser desvinculado das condições objetivas de existência, ou seja, da própria história.

$\mathrm{Na}$ concepção interacionista, a relação professor-aluno é horizontal e o professor é o mediador do processo educativo, instigando, provocando e contribuindo para que 0 aluno consiga elaborar e desenvolver seu conhecimento (MIZUKAMI, 1986). Assim, os recursos pedagógicos escolhidos devem privilegiar a valorização dos saberes prévios dos alunos, bem como a ampliação do conhecimento a partir de recursos educativos focados no sujeito de aprendizagem. Desta forma, a leitura de diferentes tipos de textos, a exploração de diferentes linguagens, a produção de textos, a discussão em Revbea, São Paulo, V. V. 13, № 1: 156-171, 2018. 
grupos, o uso de diferentes linguagens e a reflexão permanente do processo educativo, serão as ferramentas que subsidiarão a avaliação, que mais que em resultados, se traduzirá em identificação das próprias dificuldades e progressos, além de subsidiar a equipe docente para avaliar a própria prática educativa.

As contribuições de Vygotsky também orientam e influenciam visceralmente os recentes estudos e tendências da Educação. A distância existente entre o nível de complexidade de ações que um aluno executa auxiliado por alguém que tenha mais conhecimento sobre o assunto e o nível de complexidade de ações que o aluno executa de forma independente é a zona de desenvolvimento proximal analisada por Vygotsky (DANIELS 2002). Assim, as práticas educativas têm a função de mediar o conhecimento, auxiliando o aluno em seu processo educativo, na medida em que o instiga, provoca e orienta as reflexões sobre o objeto de conhecimento, considerando seu contexto social, histórico, cultural e a influência destes elementos na constituição do sujeito.

A partir destas contribuições, vale ressaltar que uma proposta de EA deve procurar atender aos diferentes estilos de aprendizagem, e cuidar para que $o$ aluno consiga transpor para a sua realidade concreta o conhecimento construído.

Considerando que a EA assume cada vez mais uma função transformadora, em um processo de co-responsabilização dos atores envolvidos, no sentido de promover o desenvolvimento sustentável, embora não seja a única, a escola torna-se uma ferramenta essencial de mediação no processo de mudança do comportamento dos seus alunos. Segundo Jacobi (2003), o desafio que se coloca é o de formular uma EA crítica e inovadora nos níveis formal e informal. Para este autor, o enfoque da proposta educativa deve buscar uma perspectiva holística de ação. O ambiente escolar é privilegiado para esta abordagem e nosso interesse no presente trabalho é exatamente verificar se a escola ocupa este espaço na formação da consciência ecológica.

Possibilitar a construção de conhecimentos significativos, articulados com a realidade social dos alunos é um desafio com que o educador ambiental se depara diariamente em seu fazer pedagógico. Entende-se que só é possível alcançar a sinergia quando há uma horizontalidade entre os saberes e uma intencionalidade explícita nas intervenções a serem realizadas. Naomar de Almeida Filho (2000), ao debater os conceitos de intersetorialidade e transdisciplinaridade, chama a atenção para a ação concreta do que convencionou chamar de "agentes científicos particulares", demonstrando que somente a prática cotidiana dos sujeitos é capaz de captar a complexidade da realidade por meio de totalizações provisórias. Isto traduz o caráter revolucionário e dinâmico da prática, pois compreende a transdisciplinaridade "como processo, estratégia de ação, modalidade de prática, e não como propriedade ou atributo de relações modelares entre campos disciplinares" (2000, p 23). 
Então, mais que uma abordagem conceitual, a intersetorialidade tornase uma estratégia de ação que pode contribuir para a apreensão da realidade e para intervenções mais significativas, na medida em que integra os diferentes saberes em torno de um projeto comum, constituindo uma rede de relação que irá construir, a partir das relações sociais estabelecidas, sua própria identidade. Ao envolver outros segmentos e sujeitos em sua proposta pedagógica, a escola possibilita a criação de um diálogo pertinente, que irá se traduzir em práticas inclusivas, mais comprometidas com a solidariedade, com a justiça social e com o respeito à diversidade.

O presente trabalho foi realizado a partir da pesquisa bibliográfica sobre a temática da EA e do processo de construção de uma cultura ecológica na sociedade brasileira. Tentou-se focalizar a noção de consciência ecológica, situando historicamente o período pós Segunda Guerra Mundial, em que a sociedade passou a esboçar reações contrárias aos impactos causados pelo desenvolvimento científico e industrial sobre o ambiente, associando a consciência ecológica com práticas sintonizadas com o conceito de sociedade sustentável, o que envolve a discussão sobre gestão social e desenvolvimento local. A partir do estudo destas referências bibliográficas, analisou-se um projeto de trabalho desenvolvido por uma escola municipal de Belo Horizonte, envolvendo alunos do $2^{\circ}$ ciclo que participam do Programa Escola Integrada ${ }^{4}$ (PEI), em parceria com um grupo de escoteiros e uma empresa de reciclagem de óleo. A proposta pedagógica analisada foi fundamentada nos princípios que norteiam a Política Nacional de Educação Ambiental, quais sejam: a participação, descentralização, reconhecimento da pluralidade e diversidade cultural e interdisciplinaridade.

Neste sentido, a pesquisa bibliográfica sobre a temática, atentou para as características que uma proposta de EA deve ter, para que seus objetivos sejam alcançados. Pensando nas diferentes maneiras de se conceber 0 fenômeno educativo, os organizadores de uma proposta de EA não podem se furtar a tentar responder a algumas questões básicas, no que se refere ao planejamento das ações educativas: Quem é o aluno? O que ele sabe sobre meio ambiente e consciência ecológica? Que conhecimentos prévios esse aluno possui, que facilitarão ou dificultarão seu processo de aprendizagem? Quais os estilos de aprendizagem serão contemplados no desenvolvimento das ações educativas? Quais recursos facilitarão a construção do conhecimento? Essas questões embasarão todo o planejamento da ação pedagógica, de forma a atender aos seus objetivos educacionais de forma satisfatória. que amplia a jornada diária do aluno na escola, contemplando aspectos de formação cidadã, social, cultural e esportiva. 


\section{O Projeto Integrar: uma experiência de integração entre saberes}

O Projeto Integrar constituiu-se de uma proposta de trabalho intersetorial, planejada em conjunto com alunos do $2^{-}$ciclo participantes do Programa Escola Integrada (PEI), escoteiros do Grupo de Escoteiros Sérgio Vieira de Mello e uma empresa coletora e recicladora de óleo vegetal usado, a Recóleo. Tratou-se de uma proposta desenvolvida no ano de 2015 em uma Escola Municipal localizada na região noroeste de Belo Horizonte. O projeto foi realizado com o propósito de criar ações direcionadas para as questões ambientais e integrar as atividades desenvolvidas na escola com outros setores da comunidade. Nesse contexto, buscou-se associar o currículo escolar às demandas da comunidade, ampliando os horizontes no conhecimento da realidade local, contribuindo para alteração dos aspectos que precisavam ser modificados e potencializando as oportunidades de aprendizagem dos alunos.

\section{Justificativa}

$\mathrm{Na}$ perspectiva de o currículo escolar contemplar questões relacionadas à sociedade e meio ambiente, e tendo em vista a promoção da interdisciplinaridade e do desenvolvimento local, o "Projeto Integrar" pretendeu estimular os alunos a refletirem criticamente sobre o uso racional do óleo vegetal, ampliando o desenvolvimento do conteúdo à participação e ao estabelecimento de parcerias, como forma de transformar de maneira endógena não só os alunos, mas também a comunidade em que a escola está inserida.

\section{Objetivo}

O Projeto teve como finalidade promover a conscientização das crianças e da comunidade sobre as questões ambientais e seus impactos em nossa vida cotidiana, incentivando a construção de ações sustentáveis e de preservação do meio ambiente.

\section{Metodologia}

Durante as atividades do Programa Escola Integrada, desenvolvido na instituição que realizou o projeto, os alunos participaram diariamente de uma oficina com atividades voltadas para as questões ambientais. Diante das discussões fomentadas, a temática que sempre ganhava foco na fala das crianças era sobre o consumo da água em nossa sociedade. Sendo esse tema de grande relevância no âmbito mundial, o Projeto Integrar foi elaborado na perspectiva de desenvolver a consciência ecológica dos alunos, estimulando pequenas atitudes que traduzem o uso racional deste importante recurso natural.

As crianças passaram a buscar informações sobre a poluição e desperdício da água e a sugerir ações cotidianas para auxiliar na preservação

revista brasileira educação ambiental 
da água. Estas discussões ampliaram os conhecimentos sobre a poluição da água, e, no processo de elaboração do Projeto Integrar, foram identificados os fatores que mais interferem na poluição das águas. Dentre estes fatores, uma aula sobre a poluição provocada pelo óleo de cozinha estimulou os alunos a pensarem em alternativas que favorecessem a noção de sustentabilidade.

Então, o que fazer com o óleo usado? Foram buscadas parcerias junto à empresa Recóleo, que forneceu material informativo sobre a temática, disponibilizou vídeos explicativos e vasilhames para armazenar o óleo usado, que seria recolhido pelas crianças em suas próprias casas e na comunidade. Parte do óleo coletado era encaminhada para a Recóleo, que, em troca, fornecia materiais de limpeza para a escola. A quantidade de material doado pela empresa dependia da quantidade de óleo arrecadado pela escola. A parte restante do óleo foi utilizada pelas crianças e escoteiros na confecção de sabão.

Assim, as crianças foram responsáveis por divulgar na escola e na comunidade o projeto e realizar a captação do óleo usado para encher os vasilhames e produzir o sabão. Diante dessa ação, pessoas da comunidade passaram a fazer o descarte de óleo na escola, o que sinaliza a influência positiva das ações desenvolvidas pela escola na comunidade local.

Parte do sabão produzido foi distribuída entre os alunos, para que apresentassem o trabalho na Feira de Ciências desenvolvida anualmente pela Secretaria Municipal de Educação. O restante do sabão foi doado aos escoteiros, para venderam na comunidade e conseguirem recursos para desenvolver as atividades de escotismo.

Vale ressaltar que, depois de pronto, o sabão era colocado em embalagens de jornal também produzidas pelas crianças. Este detalhe também foi desenvolvido pedagogicamente, tanto em oficinas de dobraduras como abordando a importância de reutilização dos recursos.

\section{Resultados}

Por meio do Projeto Integrar a escola conseguiu atingir não apenas os alunos da instituição, mas também mobilizar a comunidade nas ações previstas no projeto. Isso fica evidente quando as pessoas passaram a procurar a escola, para deixar o óleo usado de suas residências. A escola recebeu o Selo "Boas Práticas de Sustentabilidade Ambiental", fornecido pela Secretaria Municipal de Meio Ambiente em parceria com a Secretária Municipal de Educação, em reconhecimento ao trabalho desenvolvido e aos resultados obtidos pela escola. O Selo incentiva a continuidade do projeto, assim como a iniciativa de novas ações de Educação Ambiental.

Considerando-se que as ações foram planejadas e desenvolvidas a partir das vivências reais dos alunos, acrescentando a especificidade de desenvolver a compreensão sobre as relações entre a ação humana e a natureza, bem como a possibilidade de intervir conscientemente sobre a 
realidade, alterando atitudes e valores, a proposta pedagógica intentou a formação do sujeito ecológico. Esta formação condiz com ações de Educação Ambiental crítica, inspirada nos ideais emancipadores da educação popular proposta por Freire, reconhecendo os alunos como sujeitos sociais autores de práticas emancipatórias e de intencionalidades.

A despeito da experiência exitosa, nos anos seguintes a escola não deu continuidade ao projeto, uma vez que houve pouco envolvimento dos professores da escola regular, que não são os educadores que conduzem as oficinas no Programa Escola Integrada. Esta cisão entre a educação formal e a educação dita informal reproduz estudos (JACOBI, 2003; CARVALHO, 2017; GUIMARÃES, 2004) que demonstram o divórcio entre práticas emancipatórias na educação formal e os avanços conquistados pela educação informal na luta e defesa dos direitos sociais. Apesar disto, avalia-se que a prática foi decisiva na construção de cidadãos ecológicos, uma vez que notou-se o envolvimento dos alunos e da comunidade em geral. Desta forma, seria recomendável que o projeto fosse objeto de discussão da equipe docente, para que as eventuais falhas sejam corrigidas e que a proposta volte a ser desenvolvida rotineiramente pela escola.

\section{Conclusões}

Ainda que a escola não seja a única instância capaz de favorecer a consciência para um desenvolvimento sustentável, é, no entanto, um espaço privilegiado para a disseminação do conhecimento. Agregado a isto, a função transformadora da EA pode provocar a mudança de comportamentos a partir da conscientização.

A experiência analisada demonstra que o envolvimento dos alunos e da comunidade tende a potencializar o alcance das ações propostas, o que, na ótica da EA, contribui para o reconhecimento da realidade local, para o enfrentamento de potenciais dificuldades e para a propositura de ações futuras. O conhecimento produzido nesta experiência demonstrou a articulação entre o currículo escolar e a prática social dos alunos, famílias e profissionais da escola. Esta sinergia levou à constituição de saberes significativos a todos os envolvidos.

Apesar disto, notamos que iniciativas referentes a uma proposta de EA ainda são incipientes e dependem mais do envolvimento pessoal de alguns profissionais, que de uma proposta pedagógica consistente. Quanto a este aspecto, reforçamos que a Escola, enquanto espaço educativo e transformador, deve ocupar seu lugar histórico e assumir o desafio de se implantar uma cultura ecológica, sob pena de negligenciar seu principal papel, que é educar para a vida. 


\section{Referências}

ALMEIDA FILHO, N. Intersetorialidade, transdisciplinaridade e saúde coletiva: atualizando um debate em aberto. Revista de Administração Pública, v. 34, n. 6, p. 11-34, 2000.

BRASIL. Constituição Federal de 05 de outubro de 1988

BRASIL. Lei 6938, de 31 de agosto de 1981.

CARBONELL, J. A aventura de inovar: A mudança na Escola. Tradução de Fátima Murad. Porto Alegre: Artmed, 2002.

CARVALHO, I.C.M. Educação Ambiental Crítica: nomes e endereçamentos da educação. Identidades da Educação Ambiental Brasileira. Brasília: Ministério do Meio Ambiente, 2004.

CARVALHO, I.C.M. Qual Educação Ambiental? Elementos para um debate sobre Educação Ambiental e extensão rural. Agroecologia e Desenvolvimento Rural Sustentável. Porto Alegre: ,Emater, v.2, n.2, 2001

CARVALHO, I.C.M. Educação Ambiental: a formação do sujeito ecológico. São Paulo: Editora Cortez. 2017.

DANIELS, H. (org.) Uma introdução a Vygostky. Edições Loyola, São Paulo. 2002.

FREIRE, P. Pedagogia do Oprimido. Editora Paz e Terra, Rio de Janeiro, 1987.

FREITAS, M.J.C.C. A educação para o desenvolvimento sustentável e a formação de educadores/professores. Perspectiva, v. 22, n. 2, 2004.

GONÇALVES, C.W.P. Os (des)caminhos do meio ambiente. $4^{\mathrm{a}}$ ed. São Paulo: Contexto, 1993.

GUIMARÃES, M. A formação de educadores ambientais. Campinas, São Paulo; Papirus, 3를 edição, 2007.

GUIMARÃES, M. Educação Ambiental crítica. Identidade da Educação Ambiental brasileira. Brasília, Ministério do Meio Ambiente, p. 25-34, 2004.

JACOBI, P. Educação Ambiental, cidadania e sustentabilidade, Cadernos de Pesquisa, n. 118, 2003.

LAYRARGUES, P.P.; LIMA, G.F.C. Mapeando as macro-tendências políticopedagógicas da Educação Ambiental contemporânea no Brasil. Anais do Encontro Pesquisa em Educação Ambiental. v. 7, 2011.

LIMA, G.F.C. $O$ debate da sustentabilidade na sociedade insustentável. Revista de Ciências Sociais, Política \& Trabalho, v. 13, 1997.

LIMA, G.F.C. Consciência ecológica: emergência obstáculos e desafios. 1998. 
MIZUKAMI, M.G.N. Ensino: as abordagens do processo. São Paulo: Editora Pedagógica e Universitária, 1986.

MOLL, J. (Org.). Educação Integral: texto referência para o debate nacional. Brasília: MEClSecad, 2009. Disponível em: $<$ http://portal.mec.gov.br/dmdocuments/cadfinal educ integral.pdf $>$. Acesso em: 27 nov 2016.

MORIN, E. Os sete saberes necessários à educação do futuro. $12^{\mathrm{a}}$ ed. São Paulo: Cortez; Brasília, DF: UNESCO, 2007.

NAZARÉ, L.O.; ALVES, R.J.M.; PONTES, A.N.; CAVALCANTE, L.O.N.; PONTES, A.N.. Revista Brasileira de Educação Ambiental. São Paulo: V. 12, n $\mathrm{n}^{\circ}$ 5:41-55, 2017.

SILVA, M.N. A Educação Ambiental na sociedade atual e sua abordagem no ambiente escolar. Âmbito Jurídico, Rio Grande do Sul:, XV, n. 99, abr 2012. Disponível em: $<$ http://www.ambitojuridico.com.br/site/?n link=revista artigos leitura\&artigo id=11367> Acesso em: 20 dez. 2016.

VIOLA, E.J. et al. O movimento ecológico no Brasil, 1974-1986: do ambientalismo à ecopolítica, São Paulo: Anpocs, 1987. Disponível em: $<$ http://www.anpocs.org.br/portal/publicacoes/rbcs $00 \quad 03 /$ rbcs03 $01 . h t m>$. Acesso em 16 dez 2016. 